\title{
Peter Gilgen
}

\section{Im Medium der Literatur}

\author{
Versuch, einen Satz aus Oswald Eggers Val di Non zu lesen
}

\section{Das Medium der Literatur}

Jede Kunst ist auf ihr Primärmedium angewiesen als ihre notwendige, jedoch nicht zureichende Bedingung. Sprache als Primärmedium der Literatur ist nur die Grundlage des eigentlichen literarischen Mediums. Während man im Allgemeinen davon ausgeht, »daß es ein Medium schon gibt, auf das die Form zugreift« (Luhmann 2008b, 127), verhält es sich mit den Medien der Kunst gerade umgekehrt. Ein solches Medium geht der Kunst nicht voraus, sondern wird erst durch künstlerische Formen geschaffen, deren Bestand in ihnen erhalten bleibt als »ein eigenes $>$ Woraus der Selektion, ein[] Raum sinnvoller kompositorischer Möglichkeiten « ${ }^{1}$. Neue Formen verändern und erweitern dieses Medium und werden dadurch wiederum zur Voraussetzung weiterer Formen. Einer Literaturwissenschaft, die sich an der genauen Textlektüre orientiert und zugleich der Beliebigkeit und Geschichtsvergessenheit sogenannter textimmanenter Interpretationen opponiert, stellt sich die Aufgabe, historische Bedingungen und Veränderungen des von jedem Werk als Hintergrund und Widerstand mitgeführten Mediums der Literatur sichtbar zu machen und im Verhältnis zur Form des Werks zu reflektieren.

Das gegenwärtige Interesse an Varianten des distant reading, die sich eher auf Datenerhebung als Hermeneutik stützen, hat seinen Grund nicht zuletzt in der historischen Unzulänglichkeit herkömmlicher textimmanenter Verfahren. Doch gerade die Frontenbildung zwischen einem eingeschränkten, ausschließlich textbezogenen, formalistischen Verständnis des literaturwissenschaftlichen Gegenstandsbereichs und psychologischer, soziologischer und - ganz allgemein historischer Kontextualisierungen literarischen Schaffens lässt die autopoietische Konstitution des Literatursystems als Wechselspiel zwischen literarischer Form und literarischem Medium gar nicht erst in den Blick kommen. Traditioneller, der Textimmanenz verpflichteter Formalismus verlagert die Autonomie des Kunstsystems auf das einzelne Werk und ignoriert das der jeweiligen Kunstart eigene Medium zweiter Ordnung, in das ihre Formen eingeschrieben sind und durch das

1 Dazu Niklas Luhmann (2008b, 127). Für eine ausführlichere Analyse von Luhmanns Form/ Medium-Unterscheidung siehe auch Gilgen (2012).

Peter Gilgen, Ithaca

https://doi.org/10.1515/9783110690286-004 
sie erst zu den interpretierbaren Formen werden, die sie sind. Ausgeblendet wird dabei, dass jede Form als zweiseitige nicht nur ihre eigenen Elemente arrangiert, sondern immer auch den Bezug zum Medium der Dichtung mitführt. ${ }^{2}$ Wie in der strukturalen Linguistik kommt es nicht nur darauf an, was aufgerufen wird. Ebenso wichtig ist, was nicht berücksichtigt wird, aber dennoch als eine andere mögliche Variante erscheint. Die Kontingenz dieser Selektion wird erst in der Schlüssigkeit des Arrangements verwunden, was heißt, dass sie zwar nicht in eine logische, wohl aber eine ästhetische Notwendigkeit überführt werden kann.

An die Stelle der traditionellen Unterscheidung von Form und Inhalt träte die Differenz von Form und Kontext als Orientierungsrahmen literaturwissenschaftlicher Lektüre (Luhmann 2008a, 150, Anm. 24). Der entsprechende systemtheoretische Formbegriff gilt weniger der Beschaffenheit oder internen Struktur des Werks als seiner Selbstreflexivität mittels des Mediums, in das seine Form eingeschrieben und welches von dieser als Index mitgeführt wird. In diesem Sinn ist Form »unausgesprochene Selbstreferenz« (Luhmann 2008a, 150).

Im Kleinen wie im Großen überblenden die Kompositionen Oswald Eggers den prosaischen horizontalen Ablauf des Textes mit den vertikalen Assoziationen und Verdichtungen des Poetischen. Auf der gleichen Seite stehen als Prosa gesetzte Textblöcke neben strophischen Gebilden und auch graphischen Elementen und Zeichnungen, die in neueren Werken prominenter werden und entsprechend mehr Raum einnehmen. Die beiden von Egger kombinierten, sich überkreuzenden textuellen Praktiken können in Anlehnung an strukturalistische Analysen von literarischer Sprache als syntagmatische und paradigmatische Schreibverfahren bezeichnet werden. Konventionelle literarische Formen orientieren sich primär an einer der beiden Achsen. Erzählende Formen bewegen sich der horizontalen Achse entlang. Generell steht die kognitive, referentielle Funktion bei der Prosa im Vordergrund. ${ }^{3}$ Das poetische Sprechen beruht dagegen weder auf logischen noch zeitlichen Abfolgen, sondern orientiert sich an den »rapports associatifs« (Saussure 1982, 174) der paradigmatischen Achse. Diese Assoziationen können semantischer Art sein, sind aber vor allem sinnlichen Ähnlichkeiten und damit der Semiotik der Sprache geschuldet. Entkoppelt, wenn auch nicht vollends abgeschnitten, vom referentiellen Sprechen rückt die Materialität der Sprache in den Mittelpunkt. Aus diesem Grund hat Roman Jakobson die poetische Sprachfunktion als »Einstellung auf die Botschaft selber»

2 Die Zweiseitigkeit der Form wird in Spencer Browns Unterscheidungskalkül ausgearbeitet. 3 Zum Begriff und der Kategorisierung der Sprachfunktionen, vgl. Jakobson 1987, 66-71. 
definiert (Jakobson 1987, 69), denn im poetischen Sprachgebrauch fallen »Semiotik und Semantik, deren Unterscheidung die Form der Sprache konstituiert«, zusammen. ${ }^{4}$

Diese Koinzidenz führt dazu, dass die selbstverständliche externe semantische Bezüglichkeit der Sprache sich als problematisch erweist. Materialität und Selbstbezüglichkeit des Sprechens treten aus dem Halbdunkel der Konventionen und erscheinen neu und fremd. Die Automatismen der Alltagssprache werden durch schwierige poetische Formen suspendiert. Im zerklüftetem, von Bruchlinien durchzogenen Gelände muss sich die Lektüre unentwegt neu orientieren. Wort für Wort schreitet sie voran und produziert Synthesen auf Widerruf. Eine entsprechende, intensive Lektüre kann sich nicht allein auf lexikalische Erklärungen, syntaktische Rekonstruktionen und erläuternde Emendationen verlassen, sondern wird die Form eines Werks ins Verhältnis zum literarischen Medium setzen müssen, um ihren Zweck nicht zu verfehlen.

Für eine philologisch und literaturwissenschaftlich belastbare Lektüre dessen, was ein Text zu verstehen gibt, heißt dies, dass ein close reading oder eine textimmanente Interpretation, die auf historisch-kontextuelle Indizes nicht achtet, die jedes Werk als zweiseitige Form mit sich führt, die wesentliche Dimension von Literatur qua Literatur aus den Augen verliert. In ausgezeichneter Weise gilt dies für die zahlreichen ausgewiesenen und oft auch unausgewiesenen Zitate und Allusionen in Oswald Eggers Texten. Um nicht in die Irre zu gehen, bedarf die Lektüre lexikalischer und syntaktischer Merkmale ergänzender und weiterführender Untersuchungen, die dem dichterischen Medium gelten, zu dem die Form des untersuchten Werks sich verhält wie eine Figur zu ihrem Hintergrund.

Auf Oswald Eggers literarisches Werk und insbesondere das Schlusswort von Val di Non bezogen bedeutet dies, dass den vielfältigen, in den Text verwobenen Anspielungen und Querverweisen eine doppelte Funktion zukommt. Sie markieren im Medium der Literatur Eggers literarische Genealogie, deren Einzelteile im Medium lose gekoppelt vorliegen und durch die dichterische Form selegiert und fest aneinander gekoppelt werden. ${ }^{5}$ Allerdings sind feste Kopplungen keine Garantie für die innere Schlüssigkeit der Komposition. Diese ergibt sich erst aus der gesteigerten Komplexität sinnerzeugender fester Kopplungen. Es handelt sich um semantische Häufungen und mit syntaktischen Mitteln er-

4 Diese Erläuterung von Jakobsons Definition gibt Wellbery (1996, 372).

5 Luhmann (2008c) definiert den Unterschied von Form und Medium als Differenz zwischen loser und fester Koppelung. Er verallgemeinert dabei die von Fritz Heider vorgeschlagene Unterscheidung von Ding und Medium. 
zeugte Verdichtungen, die den Text überdeterminieren und ihn auf eine sekundäre Ebene gegenüber dem literarischen Medium heben. ${ }^{6}$

\section{Was nicht der Fall ist}

Literarische Form ereignet sich vor dem Hintergrund des literarischen Mediums. In diesem sind literarisch verwendbare sprachliche Elemente lose gekoppelt. Formen dagegen sind feste Kopplungen. Das literarische Medium ist notwendige, aber keinesfalls zureichende Bedingung literarischer Form. Aus diesem literarischen Fundus kann die Form sich bedienen. Sie vermag aber auch neue Elemente, ${ }^{7}$ die zuvor der Literatur fern standen, in das literarische Medium zu integrieren und dieses dadurch zu erneuern und zu erweitern. Literatur entsteht aus Literatur, ${ }^{8}$ denn Schreiben ist immer auch literarisches Wiederkäuen. Der Dichter als Wiederkäuer: ein Leser, der Wörter verschlingt, wieder hochwürgt und schließlich verdaut - zunächst nur halbwegs, dann gründlicher, auflösender, bis fast nichts mehr an ihre ursprüngliche Gestalt erinnert.

Die letzte Seite von Oswald Eggers Val di Non - Schluss und Schlüssel zugleich - enthält eine poetologische Reflexion, die nicht nur den vorausgehenden 206 Seiten gilt, sondern ganz allgemein den ontologischen Status von Dichtung zum Thema hat. Diese Nachschrift beginnt mit zwei kurzen Fragen, auf die sieben grammatikalisch komplexe Sätze folgen und Antwort geben. Durchgehend ist von Modalitäten und Möglichkeiten die Rede, die sich nicht mit der Realität decken, die aber dennoch real sein könnten.

Die erste der beiden Fragen - „Soll, was der Fall sein kann, falsch sein?«fragt nicht nur nach derartigen Modalitäten, sondern setzt sie zugleich ins Werk durch den doppelten Gebrauch von Modalverben, die das Hauptverb »sein« als Ausdruck der Existenz relativieren. Die Anspielung auf den frühen Wittgenstein

6 Roland Barthes trifft im zweiten, theoretischen Teil von Mythologies unter dem Titel »Le mythe, aujourd'hui « (Barthes 1957, 191-247) eine prägnante Unterscheidung zwischen primären und sekundären semiotischen Systemen. Als Beispiel ersterer führt er die Sprache als Zeichensystem im Sinne Saussures an: Zeichen, die aus Signifikant und Signifikat bestehen. Der Mythos - verstanden als Urform der Kunst - ist dagegen ein sekundäres semiotisches System, das Sprach- und andere konventionelle Zeichen als Signifikanten behandelt, denen er neue Signifikate zuordnet.

7 Wenn auch nicht durchgehend neue Elemente.

8 Ursprungsfragen können nur nachträglich und kontingent erklärt werden, wie Spencer Brown in seinem Differenzkalkül darlegt. 
ist nicht zu übersehen. Der Eröffnungssatz des Tractatus postuliert: ${ }^{9}$ "Die Welt ist alles, was der Fall ist. (TLP 1) Wittgenstein nennt das, was der Fall ist, »die Tatsache« (TLP 2). Von solchen Tatsachen machen wir uns »Bilder« (TLP 2.1), die »das Bestehen und Nichtbestehen von Sachverhalten vor[stellen]« (TLP 2.11). Jedes Bild ist »ein Modell der Wirklichkeit« (TLP 2.12). Allerdings enthält Wittgensteins frühe Abbildtheorie eine relevante Bedingung: »Um zu erkennen, ob das Bild wahr oder falsch ist, müssen wir es mit der Wirklichkeit vergleichen « (TLP 2.223), denn am Bild selbst lässt sich seine Wahrheit oder Falschheit nicht erkennen (TLP 2.224). Die Darstellung dessen, was der Fall sein kann, aber nicht der Fall ist, wäre demnach falsch. Eine solche falsche Rede wäre allerdings von einer unsinnigen zu unterscheiden (TLP 3.24 und 4.003).

Zusammenfassend konstatiert Wittgenstein: „Der Satz zeigt, wie es sich verhält, wenn er wahr ist. Und er sagt, daß es sich so verhält." (TLP 4.022) Eggers Poesie-Poetik legt dagegen einen Schluss nahe, der diesem Satz widerspricht und dazu herausfordert, Wittgensteins Realis durch einen Irrealis zu ersetzen: Dichtung zeigt, wie es sich verhielte, wenn sie wahr wäre. Und sie sagt, dass es sich so verhalten könnte. Denn wie in jedem Aussagesatz wird auch in einem Satz, der der Dichtung zugehört, »eine Sachlage probeweise zusammengestellt« (TLP 4.031). Allerdings hängt der dichterische Wert eines solchen Satzes gerade nicht von seinem Wahrheitswert ab. Es geht nicht darum, ob das, von dem er sagt, dass es sich so verhalte, sich tatsächlich so verhält, sondern nur darum, ob es sich so verhalten könnte. Dichtung - von Philosophen seit Platon als bloße Erdichtung desavouiert - hat ihre Modalität im Sagen des Möglichen. ${ }^{10}$ Die Werte wahr/falsch verfehlen den Sinn der Dichtung, der sich vom Unsinn ebenso unterscheidet wie von der logischen Falschheit. Daher Eggers rhetorische zweite Frage: „Kein Valeur, also veneint davon?« Will heißen: Wenn sich die Symbolik von Wittgensteins Wahrheitsmöglichkeiten nicht auf Dichtung anwenden lässt, weil immer nur ein $» \mathrm{~F}$ « herauskäme, ${ }^{11}$ wird dann nicht dichterisches Sprechen von einer Philosophie, die nur sagt, was der Fall ist, negiert und aus dem Bereich sinnvoller Sprache ausgeschlossen?

Die Paarung der beiden Modalverben »sollen « und »können« in Eggers Eröffnungsfrage erinnert außerdem auffällig an das klassische, der Moralphilosophie

9 Alle Zitate aus dem Tractatus werden, wie in der Wittgenstein-Forschung üblich, mit der Sigle TLP und den jeweiligen Absatzziffern nachgewiesen.

10 Dies geht bereits aus der Gegenüberstellung von Dichtung und Geschichtsschreibung in Aristoteles' Poetik hervor (1451b).

11 Dazu Wittgensteins Wahrheitstabellen, die er in TLP 4.31 einführt. 
Kants zugrunde liegende Prinzip, dass Sollen Können impliziere. ${ }^{12}$ Allerdings nehmen die entsprechenden Modalverben in Eggers Satz eine andere Färbung als bei Kant an. Sein »Sollen« drückt keinen Imperativ aus, der die Möglichkeit des Verlangten und damit das »Können « mit sich führt. Stattdessen verwendet Egger das Modalverb in subjektiver Bedeutung, um die wiedergegebene Behauptung in Zweifel zu ziehen, nämlich dass was der Fall sein kann, aber nicht der Fall ist, als falsch gelten solle. Eggers implizite Frage lautet: Sollen wir dieses "Sollen« als verbindlich betrachten? Die Antwort darauf gibt sein Werk, das eher zeigt als sagt, dass alles, was der Fall sein kann, aber gerade jetzt nicht der Fall ist, nicht nichts ist, sondern Nichts, das ist - eine inmitten der Affirmationen existierende, sie negierende Lücke, eine »Unfuge« im Gefüge der Propositionen, um einen suggestiven Ausdruck Eggers zu benutzen.

»Ethik und Ästhetik sind Eins." schreibt Wittgenstein (TLP 6.421), weil sie nicht betreffen, »was durch die Sprache ausgedrückt werden kann« (TLP 6.43). Durch das Kant-Echo wird dieser Befund differenziert. Die Modalverben dienen gleichsam als Leitfossilien, durch die sich ästhetische nicht nur von theoretischen, sondern auch von moralischen Sprechweisen und den zugeordneten Werten unterscheiden lassen. Dem moralisch verbindlichen objektiven Urteil steht ein subjektives ästhetisches gegenüber, das Übereinstimmung zwar fordert, sie aber nicht voraussetzen kann.

Das Schlusswort von Val di Non beginnt mit den Fragen danach, was und wie Dichtung ist, und welchen Wert sie hat. ${ }^{13}$ Die sieben Sätze, die auf die beiden Eröffnungsfragen folgen, formulieren eine Antwort aus der Perspektive der Dichtung: eine vielschichtige, vielfältige Antwort, die nicht durchgehend aus grammatikalisch wohlgeformten und logisch einwandfreien Gliedsätzen bestehen kann, sondern sich anderer sprachlicher Möglichkeiten bedient, nicht um originalen Unsinn zur Sprache zu bringen, sondern um die über Konventionen frei verfügende Dichtung in ein nachvollziehbares Verhältnis zur konventionellen Sprache zu stellen. Allerdings beziehen sich die poetisch ausgeloteten Möglichkeiten weniger auf das Primärmedium der Dichtung, die Sprache im Allgemeinen, als auf den Bestand konventionalisierter und kanonisierter dichterischer Möglichkeiten - das dichterische Medium -, in das gedichtete Formen eingeschrieben und vor dessen Hintergrund sie gelesen werden.

12 Kant formuliert dieses Prinzip in der Kritik der praktischen Vernunft: »Er urteilet also, daß er etwas kann, darum weil er sich bewußt ist, daß er es soll« (Kant 1913, 30).

13 Hier wäre die grundlegende Asymmetrie zu bedenken, die der Frage, was Dichtung sei, zugrunde liegt. In Simon Jarvis' Worten: „What poetry is, is [...] a philosophical question. But what philosophy is, is not a poetical question. So antagonistic cooperation ceases« (Jarvis 2010, 931). 


\section{3 "wo keiner mir voranging»}

Der Gegenstand dieses Essays ist der erste und längste der sieben Sätze, die auf die beiden Eingangsfragen von Eggers Schlusswort folgen. Es stellt sich heraus, dass eine Lektüre, die bei Eggers Schreiben verweilt, sich nicht ausschließlich der Aufhellung semantischer und syntaktischer Schwierigkeiten widmen kann, ohne Wesentliches aus den Augen zu verlieren. »Unfugen«, die sich nicht in eindeutige syntaktische Relationen überführen lassen, und kalkulierte semantische Unschärfen mit multidirektionaler Anschlussfähigkeit sind seit langem Stilmittel Eggers. $^{14}$

Val di Non markiert den poetischen Versuch eines neuen Anfangs, den Versuch, sich nicht einfach des Vorgefundenen zu bedienen, sondern neue Sprechweisen $\mathrm{zu}$ schaffen und so etwas, das nicht nichts ist, oder, anders gewendet, Nichts, das ist, zu sagen. Derartige Versuche, die Sprache von Grund auf zu erneuern, sind erklärter Bestandteil einer poetischen Praxis, die mindestens bis in die Romantik zurückreicht und die im literarischen Modernismus einen selbstbewussten Höhepunkt erreichte, bevor die endlose Wiederholung - gerade auch des Anspruchs auf Neuheit - zum unvermeidlichen Schicksal in postmodernen Zeiten erklärt wurde. Man wird daher nicht fehlgehen, wenn man die Negation all dessen, was vorausging und die entsprechende Suche nach dem absolut Neuen als eine ebenso paradoxe wie selbstreflexive Tradition versteht.

Erforschungen des »Nichts, das ist « stehen seit langem im Zentrum von Eggers apophatischer Poetik. ${ }^{15}$ Wie der Berg zum Tal verhält sich hier die Theologie zur Poetologie - eine strukturelle Homologie, die Egger in mehreren Werken entfaltet hat. So enthält Die ganze Zeit auf ihren ersten Seiten eingebettet in ein Augustinus-Zitat einen Verweis auf Petrarcas Besteigung des Mont Ventoux (vgl. Gilgen 2013, 292f.). Das dem magnum opus vorausgehende Buch, Diskrete Stetigkeit, beginnt dagegen mit einer eigenwilligen, nicht ausgewiesenen Übersetzung der ersten Verse von Dantes Divina Commedia, in denen der Erzähler auf halbem Weg von seinem misslungenen Aufstieg berichtet (vgl. Gilgen 2013, 292f.).

In dem auf einer Seite gesetzten, durch die kleinere Type und divergierende graphische Gestaltung vom restlichen Text unterschiedenen Schlussteil von Val di Non, der als abschließende poetologische Nachschrift gelten darf, endet der erste Satz, der auf die beiden kurzen, eingangs gestellten Fragen folgt, mit einem Zitat: »Ich habe meinen Weg, wo keiner mir voranging, selbst gebahnt, allein,

14 Alle unausgewiesenen Zitate Eggers stammen aus dem eine Seite umfassenden Schlusswort von Val di Non (Egger 2017, 207).

15 Die Verwandtschaft zwischen Eggers Formulierung und dem Schlussvers von Wallace Stevens' »The Snowman « analysiert Frederick (Frederick 2006, 72-74 und bes. 78-81). 
und unentwegt, ginge ich durch Nichts, das ist, - ins Leere. « Es handelt sich um eine zunächst akkurate, dann zunehmend freier werdende und gerade deshalb umso treffendere Übersetzung aus den Episteln des Horaz: »Libera per vacuum posui vestigia princeps, / non aliena meo pressi pede.« (Horace 1929, Epistulae 1.19.21-22), oder in Wielands klassischer Übersetzung (vgl. Wieland 2008, 290), an der sich Egger offensichtlich orientiert und die den Text des Horaz um ein Gebirge anreichert: "Ich habe meinen Weg / durch einen Strich des Helikons, wo kein / Lateiner mir vorangieng, selbst gebahnt, / nicht meinen Fuß in andrer Tritt gesezt.« Knapp zweieinhalb Jahrzehnte nach Wieland übersetzte Voß: »Frei durchdrang ich die Öde zuerst mit bahnendem Fußtritt, / Wo nicht Anderer Spur mich / leitete.« (Voß 1806, 299)

Die Verse des Horaz lassen eine entscheidende Frage offen: Was ist mit dem zu durchquerenden »vacuum« gemeint, von dem sie sprechen? Bei Egger kehrt es doppelt wieder: Auf das »Nichts, das ist«, durch das der Dichter ginge - dem dichterischen Tun entspricht das Verb in der Möglichkeitsform -, folgt die eigentliche Leere. Voß interpretiert sie nicht als freies, den Dichter lockendes Feld, sondern abwertend als »Öde», die durchdrungen und kultiviert werden will. ${ }^{16} \mathrm{Im}$ Gegensatz zu seinen beiden Nachfolgern nimmt sich Wieland die Freiheit heraus, Horaz' Vakuum zu füllen. Bei ihm führt der Weg des Dichters »durch einen Strich des Helikons, « der nur insofern einer Leere gleichkommt, als dort »kein / Lateiner mir voranging « (Wieland 2008, 290). Das schöne Bild des Horaz darf sich hier nicht frei entfalten, sondern wird an den im Gedicht dargestellten griechisch-römischen Kulturtransfer zurückgebunden, auch wenn der Übersetzer oder eher Nachdichter Wieland zu diesem Zweck den Worten des Dichters einiges zufügen muss. Wie die Epistel des Horaz in den folgenden Versen vorführt, ist es im Dichten gerade um solches $\mathrm{Zu}$ - und Hinzufügen und um freies Verfügen über tradierte Worte zu tun. Auf diese Weise sollen neue Wege, wo keiner voranging, durch die Gegend der Dichtung gebahnt werden. Wieland nennt diese Region »Helikon « und identifiziert sie mit dem Gebirge, das einst als Sitz der Musen galt. ${ }^{17}$

Der bei Wieland anstelle der Leere gesetzte »Strich« bezeichnet wohl einen Landstrich (pars regionis). ${ }^{18}$ Da die Übersetzung nicht im Bild bleibt, sondern

16 Dieser kolonialistische Anklang ist auch in der von H. Rushton Fairclough besorgten Übersetzung ins Englische in der maßgeblichen Loeb-Ausgabe vernehmbar: „vacuum « wird dort zu »virgin soil« (Horace 1929, 383).

17 Dazu die ersten Verse von Hesiods Theogonie: »Lasst uns singen von helikonischen Musen,

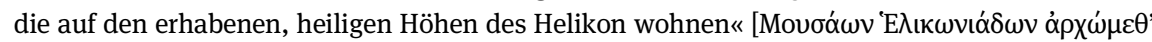

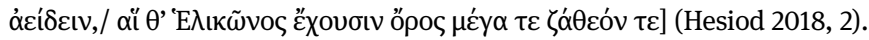

18 Die folgenden semantischen Erläuterungen stützen sich auf Grimm (Bd. 19, Sp. 1514-1549). 
mit ihren die Vorlage konkretisierenden Verweisen auf Griechen und Römer von landschaftlichen $\mathrm{zu}$ dichterischen und von räumlichen $\mathrm{zu}$ zeitlichen Verhältnissen übergeht, ließe sich der Strich in der selbstbewussten Behauptung, der Dichter habe sich »[s]einen Weg/ durch einen Strich des Helikons, wo kein/ Lateiner [ihm] voranging, selbst gebahnt «, auch anders lesen: nämlich als flüchtige, streichende Berührung der Musen (der Helikon ihre Metonymie), die erst den Dichter dazu anregt oder provoziert, sich einen neuen Weg zu bahnen. Was aber für die Griechen die Musen sind, soviel zeigt Wielands expandierte Übersetzung, verlagert sich bei Horaz ins emphatisch auftretende poetische Ich. Das Angerührtsein durch die Musen geht über in die Konfrontation des poetischen Subjekts mit der Leere. Vor dem Hintergrund des griechisch-römischen Kulturtransfers, der erst in den folgenden Versen explizit zum Thema wird, den aber Wieland im Gegensatz zum Original bereits an dieser Stelle durchexerziert, tritt die solitäre Geste des Horaz umso schärfer hervor.

Die Polysemie von Wielands "Strich« hebt die latente Paradoxie in Horaz' Original hervor: Inspiriert von griechischen Musen, die ihn im Vorbeistreichen anrühren, streicht der Dichter diese zugleich durch. Diese Selbstermächtigung im Schreiben geschieht nicht als Überwinden, sondern als Verwinden der Tradition. ${ }^{19}$ Der Dichter bahnt sich seinen Weg durch eine Gegend, in die noch keiner der Seinigen, »kein Lateiner«, vordrang, die sich aber andererseits nicht gar so leer wie bei Horaz präsentiert, denn der Strich, wie auch immer man ihn lesen will - ob als leeres Gebiet, das den Dichter herausfordert oder als zärtliche Berührung der Musen, die ihn inspiriert -, ist dem Helikon, und damit der griechischen Geographie und Mythologie zugeordnet. Wielands Version setzt den Akzent auf Tradition, allerdings um den Preis deutlicher Abweichung vom originalen Wortlaut. Denn bei Horaz steht die gewonnene Freiheit an erster Stelle, eine Priorität, an die sich Voß in seiner Übersetzung hält: »Frei durchdrang ich die Öde / zuerst mit bahnendem Fußtritt«. Die Ironie, dass der auf Kontinuität setzende Wieland gerade im Fortschreiten vom Original nicht nur dessen Sinn besser trifft, sondern ihn performativ ins Werk setzt, wird Egger nicht entgangen sein.

Eggers Verse folgen zunächst den Fußstapfen von Horaz und Wieland, nur um sie bald hinter sich zu lassen. In den der übersetzten Stelle vorausgehenden Versen sagte Horaz den sklavischen Nachäffern - »imitatores, servum pecus« (V. 19) - den Kampf an. Ihnen hält er seine dem Neuen Raum gebende, kreative imitatio entgegen. Die Schwierigkeit beim Übersetzen des Horaz besteht darin,

19 Im Gegensatz zu »überwinden« zeigt »verwinden « nicht eine bloße Negation, die das Negierte hinter sich lässt, sondern eine integrierend verformende Absorption an. Der Genitiv »Verwinden der Tradition« sollte sowohl in subjektiver als auch objektiver Bedeutung gelesen werden: Der Dichter integriert die vorausgehende Tradition, in die er sich zugleich stellt, in sein Werk. 
dieser Intention Rechnung zu tragen und sie in einen anderen literarischen $\mathrm{Zu}$ sammenhang zu übertragen, ohne dabei den Wortlaut bis zur Unkenntlichkeit $\mathrm{zu}$ entstellen. Allerdings strafte eine den Anspruch auf Originalität Wort für Wort wiederholende, die vorgezeichneten Linien nie übertretende Interlinearversion die Worte Lügen. Um Horaz' dichterischen Anspruch im neuen Kontext frei von antiquarischer Emballage $\mathrm{zu}$ Wort kommen zu lassen, wird man seine Verse wenden müssen, um sie aus den Anführungszeichen zu entlassen und in unentwegter poetischer Selbstreflexion zu verwinden. ${ }^{20}$

Diesen Vorgang, von dem der zu übersetzende Text spricht, setzt Eggers Übersetzung wiederholend und zugleich abweichend ins Werk. Der Anspruch auf Originalität, der durch Anführungszeichen und den Verweis auf Horaz vom ihn umgebenden Text abgeschottet bleibt, wird in dem Maße zu Eggers eigenem, in dem sein Übersetzen sich über die Vorgaben des antiken Dichters hinwegsetzt und in unvermessene Bezirke vorstößt. Dem poetisch angemessenen Übersetzen liegt die paradoxe Struktur von Texttreue durch Abweichung und Nachfolge durch Neuausrichtung, von der der übersetzte Text spricht, zugrunde. Daraus ergibt sich die Paradoxie, dass Egger dem Horaz genau in dem Maße folgt, in dem er sich von ihm entfernt. Darin gleicht er Wieland, dessen abweichende Übersetzung er zunächst adaptiert, nur um auch sie im nächsten Moment einer Umschrift zu unterziehen. Die erste Hälfte von Eggers Version zitiert Wieland zwar verkürzt, aber doch wortwörtlich: »Ich habe meinen Weg [durch einen Strich des Helikons], wo kein[ Latein]er mir voranging selbst gebahnt« (vgl. Egger 2017, 207). Durch eine Lücke im Text, nämlich die Auslassung der hier kursiv in Klammern gesetzten historischen und geographischen Eingrenzungen Wielands, kommt Egger dem ursprünglichen Wortlaut näher, nur um in der zweiten Hälfte des Zitats - »allein, und unentwegt, ginge ich durch Nichts, das ist, - ins Leere." (vgl. Egger 2017, 207) - sich weit davon zu entfernen und auf das Selbstzitat zuzusteuern (die idiosynkratische Verwendung von »unentwegt«; »Nichts, das ist «). ${ }^{21}$ Eggers Zitat enthält somit eine ganze poetische Genealogie, die von Archilochos (den Horaz in den folgenden Versen als den Anlass für seine Originalitätsbekundungen anführt) über Horaz und Wieland bis hin zu Egger selbst reicht.

20 In Bezug auf Heideggers Begriff der »Verwindung« vgl. Gianni Vattimos Glosse zu »Der Spruch des Anaximander (vgl. Heidegger 1980): »[W]hen critical overcoming is >distorted into the notion of Verwindung, history itself can no longer appear in its linear light. History reveals its ironic essence: interpretation and distortion, or dis-location, characterize not only the relation of thought to the messages of the past but also the relation of one sepoch others. " (Vattimo 1987, 17).

21 Dazu die ausführliche Erläuterung von Eggers »unentwegt« in Die ganze Zeit in Gilgen (2013, 297). 
Egger flicht eigene Begriffe und eigenes Denken in den Horaz. »Nichts, das ist « und »unentwegt« nehmen in seinem poetischen Vokabular zentrale Stellen ein. Ebenso das Verbum »bahnen«. Es sind Weisen des Sagens, die das von Horaz Gesagte nicht allein ins Deutsche übertragen, sondern übersetzen vom Idiom eines Dichters in das eines anderen, von einer historischen Situation in eine vollkommen anders gelagerte. Die Übersetzung kommt einem vereinnahmenden Zitieren gleich, das die Forderung des zitierten Textes gerade insofern erfüllt, als sie über ihn hinausreicht in eine Gegend der Ungleichheit. Gewichtig wird eine solche Verfahrensweise durch die Zitate der Vorgänger, deren oft subtile Veränderungen sich kaum auf den ersten Blick, sondern nur einer der historischen Distanz bewussten, kontextuellen Lektüre erschließen.

\section{Arealität}

Es ist nicht unbedeutend, dass die Frage nach poetischer Referenz sich am Ende eines Buches aufdrängt, dessen Titel - einzig in Eggers Werk - sich auf einen konkreten geographischen Ort bezieht: das Val di Non (Nonstal) in Südtirol,22 das Tal, aus dem Eggers Vater stammt. Der Ort, an dem Egger den ersten Teil seines Lebens verbrachte, liegt ein Tal weiter. Die geologischen Verwerfungen dieser Täler, von denen in Eggers Buch die Rede ist, finden in der komplexen Sprachgeographie der Region ihre Entsprechung. Hier treffen das Deutsche, das Italienische und das Anaunische, dessen linguistischer Status nicht restlos geklärt ist, aufeinander, überlagern sich und befruchten sich gegenseitig, wie Eggers multilinguistische Sprachspiele zeigen, die nicht auf die genannten Sprachen beschränkt bleiben.

Beim Wort genommen, wird der Name »Val di Non« zur Apophase. Dieses Tal ist ein Nicht-Tal, ein Tal, von dem gesagt wird, es sei nicht: ein Nichts, das im Sagen erscheint. Apophatisches Sprechen war von Anfang an ein prominentes Merkmal von Eggers Dichtung. Nichts, das ist heißt ein 2001 erschienener Band, der wie viele spätere Werke Eggers das lyrische Sprechen mit graphisch eigenständigen poetologischen und narrativen Passagen in Konstellation bringt. ${ }^{23}$

22 Eggers Buch -broich. Homotopien eines Gedichts trägt zwar im Titel auch den Namen des Ortes, Hombroich, dem die dichterische Reflexion gilt, allerdings in fragmentierter und neu agglutinierter Form.

23 Außerdem sind Zeichnungen und die gesamte graphische Gestaltung wesentliche Elemente von Eggers Publikationen. Eggers Dichten ist daher nicht bloße allographische Wortkunst; seine Bücher sind autographische Gesamtkunstwerke, die nicht einfach exzerpiert und anthologisiert werden können. Denn auch der Schriftsatz und die Gestaltung jeder Seite sind Teil der künstlerischen Arbeit. Die Unterscheidung zwischen allographischen Kunstformen (z. B. Musik), bei denen 
Als Variante des poetologischen Nichts umschreibt Val di Non einen negativen Raum, in dem Echos aus ferneren Talschaften widerhallen, sich überlagern und in der interferenziellen Verzerrung umso deutlicher vernehmbar werden. Dieses »areale Areal« - das in Eggers poetischem Sprechen im Unterschied zu einem Diskurs, der feststellt, was der Fall ist, zum Vorschein kommende Nicht-Tal - »lustriert« sein »Tempe-, Kidron-, Licenza- und Kampanertal« (Egger 2017, 207).

Das ungewöhnliche Verb »lustrieren« verdient Aufmerksamkeit. Der Duden schreibt ihm die Bedeutung »kultisch reinigen« $\mathrm{zu}$, was die weitschweifende Semantik des lateinischen »lustrare« verengt. Die Grundbedeutung war wohl »erhellen«. Neben dem späteren »reinigen, sühnen « ${ }^{24}$ wird das Verb auch in den Bedeutungen »mustern«, »umtanzen/ umringen« und »betrachten/ erwägen« verwendet. Das von Egger in den vorausgehenden 206 Seiten entfaltete »areale Areal« namens »Val di Non« umringt die genannten, literarisch bedeutenden Täler, jedes ein Ort der Dichtung, ein Gravitationszentrum, um das sich die Kultur und Literaturtradition der westlichen Welt formierten: Athen, Jerusalem, Rom, das Deutschland der Romantik.

Um mit Nietzsche zu sprechen, handelt es sich bei der Aneinanderreihung dieser mit dem Possessivpronomen »mein « versehenen Täler um den »Versuch, sich gleichsam a posteriori eine Vergangenheit zu geben, aus der man stammen möchte« (Nietzsche 1988, 270). Egger hat diese Orte auf der Landkarte der Literatur in seinen Text einverleibt. Dass seine Aneignung die genannten Täler zu erhellen vermag und sie möglicherweise auch einer Reinigung und Musterung vielleicht im Sinne einer Idealisierung - unterzieht, scheint plausibel. Allerdings ist der Aufgeräumtheit nicht zu trauen, denn in Eggers Verb wird auch Lustvolles hör- und lesbar: vielleicht als multilinguistisches Wortspiel oder als Homophonie des lateinischen Deponens lustrari und des regulären Verbs lustrare, von dem ersteres zwar semantisch weit abweicht, denn es heißt nichts anderes als »sich in Bordellen herumtreiben«, mit dessen Passivformen es allerdings übereinstimmt, als wäre eine spätere, zweifellos notwendige Reinigung bereits als Gegensinn im unreinen Tun angelegt. Die Absicht, diese Täler als literarische Denkmäler und Teil der Literaturgeschichte sowie des verfügbaren literarischen Mediums zu erhellen, wird von der Möglichkeit einer lustvollen, geradezu anrüchigen, und etablierten Konventionen zuwiderlaufenden literarischen Liaison herausgefordert, die sich als umso fruchtbarer erweist.

das eigentliche Werk nicht ein bestimmtes materielles Objekt ist, sondern sich in jeder Aufführung von Neuem darstellt, und autographischen Formen (z. B. Malerei), in denen unwiederholbare Originale geschaffen werden, geht zurück auf Goodman (1976, 113).

24 Dazu auch das Substantiv »lustrum« in der Bedeutung von Reinigungs- oder Sühneopfer, wie es von den römischen Zensoren am Ende ihrer Amtszeit dargebracht wurde. 
Jedes der angeführten Täler hat einen konkreten geographischen und historischen Bezug. Gegenwärtig sind sie aber vor allem als literarische, durch die Literatur geformte Entitäten. Ovid erzählt im ersten Buch seiner Metamorphosen von Apollo, der sich im Tempetal (Ovid 1977, 42, V. 568) in Thessalien in die Nymphe Daphne verliebte, während Vergil im vierten Buch der Georgica inmitten einer anderen Geschichte darauf zu sprechen kommt, dass Eurydike in Tempe (Ovid 1977, 24, V. 317) durch einen Schlangenbiss zu Tode kam, als sie vor Aristaeus' Zudringlichkeiten flüchtete. Diese kurze Abschweifung gilt als älteste ausführliche Darstellung des Eurydike-Mythos, ${ }^{25}$ dessen geläufige Variante die an Vergil anknüpfende, erweiterte Version in Ovids Metamorphosen ist, in der Orpheus, der Prototyp des lyrischen Dichters, die Hauptrolle spielt (Ovid 1958, 2-8, V. 1-77). ${ }^{26}$ Erst die beiden Römer gaben Eurydikes in Griechenland angesiedelter und in die griechische Mythologie verwobener Geschichte ihre klassische Form.

Das Kidrontal verläuft östlich der Altstadt von Jerusalem zwischen Tempelberg und Ölberg. Es findet in der Hebräischen Bibel wiederholt Erwähnung, etwa als König David sich gezwungen sah, bei der Flucht vor seinem rebellischen Sohn Absalom den Kidron zu überqueren (2. Sam 15,23). Innerhalb des Neuen Testaments wird der »Bach Kidron« im Johannes-Evangelium erwähnt, als Jesus, ein Abkömmling Davids, ${ }^{27}$ nach dem Abendmahl mit seinen Jüngern sich auf den Weg in den Garten Gethsemane am Fuß des Ölbergs macht, wo ihn Judas verraten wird (Joh 18,1-2). Diese Textkonstellation lässt sich aus nachträglicher, christlicher Perspektive typologisch lesen: Was sich im Alten Testament ankündigt, findet im Neuen seine Erfüllung. Darüber hinaus wurde das Kidrontal zunächst in der jüdischen Tradition und schließlich in der Überlieferung aller drei abrahamitischen Religionen mit dem Tal Josafat, der Stätte des Weltgerichts, identifiziert. ${ }^{28}$ Am Ende der Tage werden die losen Fäden an diesem Ort zusammenlaufen (Beer 1921, 114).

25 Bei Platon, der im Symposion (179d-e) Orpheus Abstieg in die Unterwelt erwähnt, wird dagegen der Name der gesuchten Frau nicht erwähnt. Orpheus darf sie in dieser Version nur als Erscheinung sehen, weil er - anders als die von Platon zuvor erwähnte Alkestis (179b-d) - nicht willens war, für seine Liebe zu sterben.

26 Ovids Version stellt Orpheus' vergeblichen Versuch, Eurydike aus der Unterwelt zurückzuholen, ins Zentrum. Aristaeus bleibt unerwähnt. Eurydike stirbt nicht in Tempe, sondern in Orpheus' Heimat, Thrakien.

27 Vgl. die Genealogien am Anfang des Matthäusevangeliums und im Lukasevangelium (Luk 3,23-38). Jesus folgt nach zweimal vierzehn Generationen auf David (Matth 1,17).

28 Die entsprechenden Stellen in der Hebräischen Bibel sind Joel 4,2 und 4,12. In Luthers Version ebenso wie in der King James Übersetzung sind dagegen das zweite und dritte Buch Joel zu einem einzigen Buch verbunden. Ihr Buch 3 entspricht somit dem Hebräischen Buch 4. 
In den Sabiner Bergen unweit von Rom im Val di Licenza, dessen Name im Zusammenhang von Eggers poetologischer Genealogie auch als val di licenza poetica gelesen werden sollte, lag das Landhaus des Horaz. Der 127 Wörter lange, gewundene Satz, der mit Eggers Aufzählung literarisch prominenter Täler beginnt, endet, wie oben besprochen, mit den berühmten Versen, in denen Horaz seine dichterische Arbeit selbstbewusst ins Verhältnis $\mathrm{zu}$ seinen griechischen Vorbildern stellt.

Schließlich das in den Pyrenäen liegende Kampanertal: Es verhilft einer von Jean Pauls kleineren erzählenden Schriften zu Titel und Handlungsort. Die Erzählung enthält eine Passage, die ein Schlaglicht auf Eggers Häufung von Tälern wirft. Jean Paul beschreibt die Scheidung besonderer Orte von ihrem reizlosen Umfeld als chemisch-alchemistischen Vorgang: Eine imaginäre »Destillation« trennt »das Phlegma der Erdkugel [...], die Polarwüsten, die Eismeere, die russischen Wälder« und anderes Unliebsames mehr vom Rest, aus dem sich »eine schöne Nebenerde« extrahieren läßt (Jean Paul 2000, 569). Der Dichter empfiehlt, mustergültige Landschaftselemente frei zu kombinieren: die Höhle von Antiparos; die Rheinebenen; den Ätna, ${ }^{29}$ Tabor und Mont Blanc als ideale Berge; die Freundschaftsinseln und die Pappelinsel im Park von Ermenonville ${ }^{30}$ als schönste Inseln, und so fort (Jean Paul 2000, 569). Als geeignete Täler schlägt er das Seifersdorfer Tal ${ }^{31}$ und das Kampaner Tal vor. Durch die empfohlene dichterische Destillation oder Lustration wird »neben dieser wüsten schmutzigen Welt die schönste Bei- und Nachwelt« zu unserem Besitz (Jean Paul 2000, 569): ein areales Areal als Ort des Dichtens, wobei der Genitiv zwischen subjektiver und objektiver Bedeutung changiert, denn die Rede ist von einem imaginären Bezirk, den Dichtung eröffnet und der zugleich dem Dichten erst Raum gibt.

Für Jean Paul ist das Kampaner Tal ein solcher imaginärer Ort, den er selber, wie er seinen Lesern unterstellt, nur aus Arthur Youngs Reisebericht und allenfalls aus "geographischen Schulstunden« kennt (Jean Paul 2000, 569). Young orientierte sich am Nützlichkeitsdenken. Dem eigentlichen Reisejournal, das er erst auf Anraten eines Freundes unverändert veröffentlichte (Young 1792, 2f.), folgen im zweiten Teil seines Buches Berichte, die vor allem landwirtschaftliche Themen (Klima, Bewässerung, etc.) behandeln. Die ästhetischen Reize des Kampanertals werden im ersten Teil nur kurz gestreift. Die Stelle beginnt mit Youngs Eingeständnis, dass er von diesem Tal zwar schon Großartiges gehört, dass es aber seine Erwartung trotzdem bei weitem übertroffen habe - »of which I had heard

29 Jean Paul spricht vom »Hybla«; eine Stadt dieses Namens lag einst am Südhang des Ätna, wie der Herausgeber Norbert Miller anmerkt (Jean Paul 2000, 1186).

30 Miller macht genauere Angaben zur Pappelinsel (Jean Paul 2000, 1158).

31 Nach Miller ein »waldreiches Tal in der Gegend von Dresden« (Jean Paul 2000, 1187). 
great things, and which yet much surpassed my expectation « (Young 1792, 40) -, und endet mit dem Befund, dieses Tal sei »the landscape, which is upon the whole the most exquisite for form and colour that my eye has ever been regaled with« (Young 1792, 41) 32 - Anlass genug für Jean Paul, sie in eines seiner »Paradiese der Phantasie« zu verwandeln, die "nie verloren, sondern stets erobert» werden (Jean Paul 2000, 570). Überhaupt sei die Dichtkunst der »Leier des Orpheus' « vergleichbar: Wie diese die symplegadischen Felsen bringe jene die »zwei zermalmenden Felsen« von Vergangenheit und Zukunft zum Stillstand (Jean Paul 2000, 570). ${ }^{33}$ Der erste Dichter sicherte durch seinen Gesang die Durchfahrt der Argonauten durch die Meerenge am Bosporus. Die Dichtkunst seines Nachfahren dagegen »söhnet die Vergangenheit mit der Zukunft aus« (Jean Paul 2000, 570), um in einer erweiterten, »die ganze Zeit [...] aufblätter[nden]« Gegenwart zu verweilen (Egger 2017, 207). Anders als die Momente unserer realen Existenz, ist solch dichterisches Weilen von der Sorge um Zukünftiges (etwa Youngs Nützlichkeitserwägungen) ebenso befreit wie von der Bestimmung durch Vergangenes, über das es souverän verfügt.

Jean Paul unterscheidet das zum Ideal erklärte Kampaner Tal sowohl vom mythologisch überfrachteten Tempetal als auch vom real existierenden Rosental, einem Ausflugsziel bei Leipzig. Am ehesten ließe er es, »wenn ich zu sprechen hätte, [...] verschütten [...] mit Utopien« (Jean Paul 2000, 569). Als erdichtete Gegend, als areales Areal gleicht es diesen Nicht-Orten. Eggers Serie von Tälern operiert dagegen weniger als chemische Scheidung, sondern eher als Überblendung oder Absorption. Dichtungstraditionen, die sein Werk informieren, und geographisch-geologische Gegebenheiten werden übereinander geschichtet, verwoben, verdrillt: Die griechische Mythologie und ihre römischen Bearbeitungen; die Erzählungen in der Hebräischen Bibel und ihre typologischen Entsprechungen im Neuen Testament; die von Horaz adaptierten Jamben des Archilochos und neuere Adaptionen des Horaz; Jean Pauls Verwandlung von Youngs eher prosaischer Beschreibung in Dichtung; schließlich Eggers eigene Adaption von Wielands HorazÜbersetzung und die genau beschriebenen Bruchlinien und Gebirgsfaltungen des Val di Non. Sie alle gehen ein in Eggers »Zwirn der Erinnerung (Egger 2010, 479). Zu den bereits erwähnten Fäden werden sich in den noch ausstehenden Sätzen von Eggers Nachwort weitere hinzugesellen. Auch ein Hölderlin-Faden (»von Klippe zu

32 Jean Paul benutzte die mir nicht zugängliche deutsche Fassung Reise durch Frankreich und einen Teil von Italien in den Jahren 1787-90, die von 1793 bis 1795 in drei Teilen erschien, wie Miller anmerkt (Jean Paul 2000, 1187).

33 Vgl. Jean Pauls Anmerkung (Jean Paul 2000, 570, Anm. 1). Miller weist als Quelle auf das spätantike Epos Argonautica Orphica, in dem Orpheus die Symplegaden zum Stillstand bringt, um den Helden die Durchfahrt zu ermöglichen (Jean Paul 2000, 1187). 
Klippe«) und ein Mallarmé-Strang (»le livre« und »Ptyx«) sind prominent in diesem poetischen Garn verzwirnt. Für die Lesenden sind die Ingredienzien, mit Eggers schönem Bild gesprochen, »im offenen Buch ruminant aufgeblättert«.

Die Grammatik lässt kein abschließendes Urteil darüber zu, ob Eggers »Tempe-, Kidron-, Licenza- oder Kampanertal« das areale Areal des Val di Non lustriert oder dieses jenes. Der Relativsatz lässt sich wie ein spekulativer Satz in beide Richtungen lesen, je nachdem ob das Relativpronomen »welches« als Nominativ oder Akkusativ verstanden wird. Dies heißt aber auch, dass hier die Vergangenheit nicht einfach negiert, sondern überschrieben und umgeschrieben wird. Das aufgerufene Vergangene wird in seiner Umschrift mit- und weitergeführt. Es wird nicht in archivarischer Absicht zitiert, sondern das Zitierte wird ganz im Gegenteil aus den Anführungszeichen entlassen. Im Bezug auf seinem neuen Kontext wird es gegenwärtig.

In Die ganze Zeit unterscheidet Egger seine »Verfahrensweise« (ein an Hölderlin erinnernder Begriff), die darin besteht, "Texte wie Intarsien zu mischen« von den »Beliebigkeiten der Bricolage«, denn anders als diese hebe jene die »Landschaftslosigkeit« der aneinandergefügten Worte und Wortabschnitte auf (Egger 2010, 139). Durch die im Nachwort von Val di Non wieder aufgenommenen »mosaizierende[n] Intarsi/en« verläuft eine einen Anschlag breite Nut oder Aussparung, die senkrecht und symmetrisch die Seite in zwei Textblöcke zerteilt. Diese Visualisierung verdeutlicht, dass Intarsien nicht als organische Ganzheiten, sondern als minuziöse Kompositionen zu verstehen sind. Es handelt sich, wie in Die ganze Zeit beschrieben, um die Versetzung von »Sätzen und Sentenzen mit einbildungskräftigen Perioden aus dem abstrakten Nirgendwo in eine Situation, in der »die Kulisse sprichwörtlicher Geschehnisse« sich vor den leeren Hintergrund schiebt (Egger 2010, 139). Diese Betrachtung leitet Egger durch ein Zitat aus dem Horaz ein, eine freie Umschrift der Eröffnungsverse der Ars poetica. ${ }^{34}$ Die dichterische Herausforderung besteht darin, ein Zitat nicht nur aus seinen ur-

34 Die Verse 1-5 der Ars poetica [Epistula ad Pisones]: »Humano capiti cervicem pictor equinam/ iungere si velit et varias inducere plumas/ undique collatis membris, ut turpiter atrum/ desinat in piscem mulier formosa superne,/ spectatum admissi, risum teneatis, amici?« (Horace 1929, 450) werden von Egger nicht eigentlich übersetzt, sondern abgewandelt und neu kombiniert: "Ich will die ganze Zeit zum Schädel eines Menschen Nacken von zwei Rossen fügen und Füße, vielgliedrig zusammengezuzelt, mit Rotz und Ruß verkleben wie Horaz, so daß Gefieder in Fische mit verquaster Nase (als ohne Hals und Rumpf) verwandelt sei die Eselei.« (Egger 2010, 139) Die thematische Verwandtschaft ist deutlich genug, auch wenn Egger hier frei mit dem Ausgangsmaterial hantiert. Bemerkenswert ist, dass Eggers prosaische Passage mit einem vierfüßigen Jambus endet, der auch einen Reim einschließt und die Prosa poetisch durchkreuzt. Zur Auseinandersetzung mit der Ars poetica gehört im Übrigen auch Eggers programmatischer Hinweis auf »die ganze Zeit«, der nicht nur den Titel des eigenen Buchs zi- 
sprünglichen Bezügen zu lösen, sondern es neu zu situieren, um seine »Nachreife« zu befördern (Benjamin 1991, 12f.). Die Artifizialität dieser literarischer Intarsientechnik steht im Gegensatz zum romantischen Ideal des Organischen. Eggers nicht selten frappante Textkonstellationen sind bewusst und erkennbar konstruiert.

Der Satz, dem unsere Lektüre gilt, beginnt mit der Aufzählung von arealen, literarischen Arealen und endet mit Eggers Übersetzung von Horaz' Versen. Zwischen diesen selbstreflexiven poetologischen Polen breitet Egger in den Verästelungen seiner Nebensätze eine doppelte Beschreibung von Buch und Tal aus. Der erste der beiden Pole ist eingebunden in den kurzen Hauptsatz. Sein grammatisches Subjekt, das »areale Areal« (ein Begriff, der in Eggers Werk eine lange Tradition hat) bezeichnet ein Zwischenreich: Als areales ist es zwar nicht etwas, das ist, aber insofern es sich um ein Areal handelt, dessen Erkundung mitteilbar ist, ist es auch nicht nichts. Für diese Art poetischer Entität fand Egger die Formel »Nichts, das ist«, die 2001 einer poetologisch-poetischen Reflexion den Titel gab. Dieses Areal der Dichtung, dessen ontologischer Status in der Schwebe bleibt, leitet den kurzen, von langen Nebensätzen, Appositionen und Einwürfen unterbrochenen, ergänzten, und gedehnten Hauptsatz ein und konstituiert sein grammatisches Subjekt: »Das areale Areal [...] istert« (Egger 2017, 207).

Wäre es denkbar das Verb »istern« auf das intransitive, existenzielle »Ist« zu beziehen, analog zum Verhältnis von "geistern« und »Geist«? Das ungewöhnliche Verb wäre dann nicht als direkter Ausdruck der Existenz zu verstehen, sondern eher als zwischen Sein und Nicht-Sein oszillierendes Tun, als ein Tun des Seienden, das trotz seines unklaren ontologischen Status seiende Spuren hinterlässt: Das Areale geistert gleichsam seiend herum. Das Verb ließe sich außerdem in Bezug auf den Namen »Ister « lesen, der, abgeleitet vom griechischen »Istros«, in der Antike die Donau bezeichnete. ${ }^{35}$ Heute ist die Bezeichnung vor allem durch Hölderlins unvollendete, dem Fluss gewidmete späte Hymne vertraut, $^{36}$ der Heidegger eine Vorlesung widmete. Mehrere Stellen dieser Hymne lehnen sich an Pindars 3. Olympisches Siegeslied an, dessen Anfang Hölderlin übersetzte (Hölderlin 2005, 1029). Die »gelben Ufer« zitieren außerdem auch den

tiert, sondern auf die Poesie als Zeitkunst (in Lessings Sinn) rekurriert und sie Horazens Rede vom »pictor « gegenüberstellt.

35 Während »Istros« der griechische Name für den Fluss war, bezeichnet das römische »Ister« oder auch »Hister« streng genommen nur seinen unteren Teil. Der Oberlauf wurde dagegen »Danuvius« genannt.

36 Die wahrscheinlich um 1803 entstandene Hymne ist ohne Titel überliefert (vgl. Hölderlin 2005, 362-364). Vers 21, aus dem der Titel abgeleitet wurde, lautet: »Man nennet aber diesen den Ister.«. 
vom Ister herumgewirbelten " gelben Sand « in Vergils Georgica. ${ }^{37}$ Es scheint plausibel, dass das kursiv gesetzte Verb »istern« sich auf Hölderlins Gedicht bezieht und sich mindestens ebenso deutlich von ihm herleitet wie von dessen vordergründigem Referenten. Das in Frage stehende Tun wäre dann weniger die dem Mäandrieren des Flusses vergleichbare Bewegung von Eggers Satz, sondern bezöge sich vor allem auf die unentwegte Selbstreferenz von Dichtung, konkret auf die in Hölderlins Hymne eingeschriebene Ahnenreihe Pindar - Vergil. Ihr wird hier Hölderlin angefügt, den Egger weiter unten, im vierten Satz seines Schlussworts, zitiert: »von Klippe zu Klippe« (Egger 2017, 207). Dass Hölderlin genau diesen Ausdruck aus dem ursprünglich 1799 im zweiten Band seines Romans Hyperion erschienen »Schicksalslied« drei Jahre später im Gedicht »Stimme des Volks« (Zweite Fassung) wieder aufnahm und Egger ihn schon in Prosa, Proserpina, Prosa variierte, gibt der skizzierten poetologischen Genealogie ihre selbstreferenzielle Pointe. ${ }^{38}$

Dem neologistischen Verb »istern « in diese historisch-poetologischen Abgründe $\mathrm{zu}$ folgen, die nur anzudeuten, in ihrer nahezu unendlichen Ausdehnung aber nicht zu vermessen sind, führt uns paradoxerweise nicht aus Eggers Text hinaus, sondern ganz im Gegenteil tiefer in ihn hinein. Der zwischen dem grammatischen Subjekt des Satzes, dem arealen Areal, und dem Prädikat »istert«, eingeschobene Relativsatz erinnert an die parallele poetische Genealogie von Eggers Val di Non: »Das areale Areal [...] lustriert« Eggers »Tempe-, Kidron-, Licenza- und Kampanertal« (Egger 2017, 207). Bemerkenswert ist hier zunächst die im sprachlichen Material deutlich werdende Verschränkung der beiden den Relativsatz und den ihn umklammernden Hauptsatz bestimmenden und im Text direkt aufeinander folgenden Verben. Bei »lustriert« handelt es sich - abzüglich der ersten beiden Buchstaben »l« und »u« - um ein Anagramm von »istert«. Es bleibt unentscheidbar, welches von beiden - die gegenseitige Erhellung oder die ontologische Anbindung - der Ruf und welches das Echo ist.

Die übrigen zwei Buchstaben »lu« bilden das Partizip Perfekt des französischen Verbs »lire« [lesen]. Unmittelbar voraus geht ihnen das vierfache Tal. Eggers Val di Non ist vor allem ein »val lu«, ein gelesenes eher als ein gewesenes Tal: weniger die Darstellung eines Tals, das ist, wie es ist, sondern eher selbst eines, das Nichts ist, das ist, und von den Tautologien und Negationen der Logik unberührt bleibt. Die Kontraktion von »val lu« ergibt »valu«. ${ }^{39}$ Das heißt: Die Serie literarischer Täler, in die Egger sein eigenes Val di Non stellt, sind es

37 Georgica III, v. 350: »torquens flaventis Hister harenas«. Die gelbe Farbe rührt, wie Schmidt erläutert, vom gelblichen Kalkstein der Schwäbischen Alb (vgl. Hölderlin 2005, 1030).

38 Eggers Umwandlung der Hölderlin-Passage in Prosa, Proserpina, Prosa (Egger 2004, 51) wird von Gilgen (2012, 58f.) kommentiert.

39 Die Ausdrücke sind ohnehin homophon. 
wert, gelesen zu werden. Sie sind nicht nur Objekte, sondern auch Produkte der Lektüre, etwas, das der Fall sein kann und dessen »Valeur« gerade in dieser Möglichkeitsform liegt.

\section{Ruminatio}

Wie Quintilians Beispiel zeigt wird »imitatio« in der Antike als Verdauungsvorgang aufgefasst. ${ }^{40}$ Zum Zwecke späterer Nachahmung wird Gelesenes in seine Elemente zerkleinert und im Gedächtnis gespeichert. Eggers abgewandeltes HorazZitat kann als Erneuerung und Fortsetzung dieser Tradition oder zumindest als Reverenz an sie gelesen werden. Allerdings weist der unmittelbar darauf folgende Satz in eine andere Richtung: Die Rede ist von ruminatio, die Egger wörtlich als Wiederkäuen versteht. Der dritte Magen der Wiederkäuer [omasum] wird seiner Gestalt wegen »Blättermagen« oder auch »Buch« genannt. Dutzende von Schleimhautfalten [laminae omasi], die den Blättern eines aufgeschlagenen Buches gleichen, bedecken seine Innenseite. Die in den mittelalterlichen Klöstern praktizierte, das Wiederkäuen im Namen tragende ruminatio steht für eine geradezu körperliche Einverleibung der Heiligen Schrift durch intensives, regelmäßig wiederholtes Lesen, das auf »die Extraktion des geistlichen, insbesondere moralischen Schriftsinnes« abzielt (Butzer 2007, 49). Egger dagegen verfremdet die eingespielte Metaphorik dieser lectio divina durch sein Wörtlich-Nehmen der Physiologie des Wiederkäuermagens und stellt dadurch ihren Sinn in Frage. Dies bedingt einen Wechsel der Perspektive. Egger denkt nicht vom Buch her, das metaphorisch als eine Art Magen verstanden werden soll, sondern er kehrt das Verfahren um: »Buch« meint hier »den dritten Magen der Wiederkäuer, auch Psalter, Löser, Kalender, Blättermagen, Hundertkammer, Mannigfalter -«. Die aus Johann Conrad Peyers Merycologia; sive, De ruminantibus et ruminatione commentarius zitierte Nomenklatur mag ungewöhnlich scheinen, sie war jedoch über Jahrhunderte und in einer Anzahl von Sprachen gebräuchlich. ${ }^{41}$

An dieser Stelle erweist sich der Blättermagen als »Buch«, das selbst gelesen werden will. Das heißt, die als Wiederkäuen konzipierte und auf Sinnex-

40 Dazu Buch X.1.19 der Institutio Oratoria (Quintilian 2002, 260).

41 So erklärt etwa der österreichische Agronom Bernhard Petri in seinem Standardwerk zur Schafzucht: »[V]on diesen verschiedenen Magen, nennt man den ersten oder Wiederkauungsmagen, den Wanst, Bansen, Gras- oder Doppelmagen; den andern die Haube, Mütze, Hülle oder Zellgewebe; den dritten den Mannigfalter, das Buch, den Blättermagen, den Psalter oder das Tausendfach; den vierten endlich den Laab-, Fett- oder eigentlichen Verdauungsmagen« (Petri 1825, Bd. 1, 249). 
traktion zielende lectio divina bedarf selbst einer Lektüre, die gerade nicht von ihren materiellen und medialen Bedingungen absieht, sondern diese herausstellt. Es geht darum, das Angelesene und die Art der Lektüre simultan zu erfassen. Eggers Methode des verfremdenden Zitierens dient dazu, diese Verschränkung von angeeigneter Vorlage und eigentlicher Aneignung als poetisches Grundprinzip sichtbar zu machen.

Die beiden historisch aufeinander bezogenen, aber auf deutlich unterschiedenen Praktiken beruhenden Traditionslinien der antiken imitatio und der mittelalterlichen ruminatio werden schließlich in der vom Humanismus konzipierten »Physiologie der imitatio« (Butzer 2007, 49) vereint. An vorderster Stelle steht hier Petrarca, der ein originelles imitatio-Konzept entwickelte. ${ }^{42}$ Anders als die mittelalterlichen Mönche, die sich durch die Lesepraxis der ruminatio das heilige Wort einzuverleiben suchten, liebte Petrarca »seine Bücher [...] als Bücher« (Gmelin 1932, 101). Seine Nachahmung der antiken Autoren wich in der Ausführung bewusst vom Vorbild ab. Genauso verhält es sich mit Petrarcas Aneignung von Quintilians Theorie der imitatio: Er knüpft an sie an, nicht ohne ihr durch die Forderung, das Übernommene im eigenen Stil neu zu gestalten, selbst eine neue Gestalt zu geben. Dieser Abweichung entspricht, dass sich Petrarcas Poetik, wie Günter Butzer gezeigt hat, »auch aus monastischen Praktiken (im wahrsten Sinne des Wortes) speist«, denn imitatio wird in seiner Theorie konsequent durch ruminatio ergänzt bis hin zum Punkt, an dem »das zu imitierende Werk nicht mehr als solches erkennbar ist (Butzer 2007, 49f.). Dies provoziert die Frage, inwiefern es sich bei Petrarcas Verfahren überhaupt noch um imitatio handelt. Oder liegt gerade in solch vollständiger Aneignung und Umformung die letzte Konsequenz des physiologischen Modells der Nachahmung? Wie bei der Verdauung wird das Aufzunehmende in seine Teile zerlegt, um dann nach Maßgabe des Aufnehmenden verarbeitet zu werden. ${ }^{43}$

Doch inwiefern betreffen Eggers Überlegungen zur ruminatio den ersten der Sätze, die auf die Eingangsfragen seiner Nachschrift Antwort geben? Der zweite Satz, der vom Wiederkäuen handelt, schließt mit der Kausalkonjunktion »denn« an den ersten an. Die zu erwartende Begründung bleibt allerdings aus. Die beiden Sätze stehen unvermittelt nebeneinander. Was sie verbinden könnte, wird nicht auf der Ebene der Satzaussage mitgeteilt. Eher wird es sich zeigen müssen. Entscheidend ist die Frage, was Horaz' Überlegungen zu Originalität und Nachahmung mit dem Wiederkäuen zu tun haben. Antwort darauf gibt ein Brief in

42 Gmelins Studie enthält eine Rekonstruktion von Petrarcas Theorie der imitatio (Gmelin 1932, 118-127).

43 Butzer analysiert in seinem Aufsatz die Theorie und Metaphorik dieser Prozesse ausführlich. 
den 24 Bücher umfassenden Epistolae familiares, der Sammlung von Petrarcas literarischen Briefen, die durch seine Entdeckung von Ciceros Briefen angeregt wurde.

An zweiter Stelle im 22. Band nimmt ein Brief an den Dichterkollegen Boccaccio zu Fragen von Originalität und Nachahmung ausführlich Stellung (Petrarca 2017, 334-349). Anlass ist Petrarcas Eingeständnis, beim Wiederlesen seines Bucolicum carmen, das Boccaccio kennt, auf bekannte Stellen gestoßen zu sein. Gerade die sehr intensive Lektüre der von ihm verehrten Dichter - Petrarca erwähnt Vergil, Horaz, Boethius und Cicero - führe dazu, dass sie nicht einfach in sein Gedächtnis aufgenommen würden, »sed medullis affixa sunt unumque cum ingenio facta sunt meo« [sondern sich ins Mark einprägten und sich mit seinem Wesen vereinten] (Petrarca 2017, 340). So sehr sind diese Texte ein Teil von ihm, dass er sie nicht vergessen wird, selbst wenn er sie nie wieder liest. Aber, dies ist die ungewollte Konsequenz restloser Aneignung, »interdum obliviscar auctorem« [zuweilen würde ich den Verfasser vergessen]. Weder kann sich Petrarca daran erinnern, woher manche der Passagen stammen, noch daran, dass sie fremdes Gut sind.

Ist nicht dies die letzte Konsequenz einer Textbehandlung, die der klösterlichen ruminatio aufs Haar gleicht, auch wenn ihre Motivation eine ganz andere ist? Und welche Maßnahmen könnten hier Abhilfe schaffen? Das Problem stellt sich nicht bei Texten, bei denen Petrarca kaum verweilt, denn aus ihnen entnommene Passagen kann er als fremd und ihm nicht zugehörig erkennen. Diese Texte bleiben auch in anderer Hinsicht folgenlos für ihn. Das Problem betrifft jene Texte, die seine Aufmerksamkeit auf sich ziehen und nach einer intensiven Lektüre verlangen, die bei ihnen verweilt und nach Wiederholung verlangt. Das Ideal der antiken imitatio geht hier unmerklich und vor allem unweigerlich in eine Art von ruminatio über. Um aber nicht vom Eindruck dieser Schriften überwältigt zu werden und sie so vollständig wiederzukäuen, dass nicht der Lesende sich den fremden Text aneignet, sondern dieser jenen von innen heraus steuert, müssen Vorkehrungen getroffen werden. Denn anders als bei Horaz und Quintilian liegt das Problem der imitatio für Petrarca nicht primär darin, dass sie zu oberflächlich und äußerlich sein könnte. Ganz im Gegenteil geht die Hauptgefahr von einer Nachahmung aus, die so vollständig vom Nachgeahmten erfüllt ist, dass sie sich diesem übereignet und unter seinem Eindruck nicht mehr zu sich selbst kommt. Petrarca will daher sein Schreiben von Stellen, die er sich angeeignet hat, frei halten, «nisi vel prolato auctore vel mutatione insigni« [außer wenn der Autor zitiert oder deutliche Veränderungen angebracht werden] (Petrarca 2017, 340-342). Die einzelnen Elemente sollen getrennt gehalten werden, genau wie die Bienen es tun, wenn sie aus vielen Zutaten eine einzige Substanz produzieren. Angespielt wird hier auf das wirkungsmächtige 
Bienengleichnis Senecas, ${ }^{44}$ in dem der Philosoph dazu rät beim Schreiben die Bienen nachzuahmen - »apes debemus imitari« (Seneca 1999, 224). Die zusammengetragenen »libamenta« [Lesefrüchte] sollen getrennt aufbewahrt werden und erst in der kreativen Arbeit zusammenfließen (Seneca 1999, 226).

Im Unterschied zu seinen antiken Vorgängern legt Petrarca keinen Wert darauf, der Erste zu sein, der in bisher unbegangenes Gebiet vordringt. Anders als Juvenal, Horaz, Lukrez und Vergil, deren Ansprüche auf Priorität und Originalität er zitiert, geht es ihm darum, seine dichterischen Formen bewusst ins Verhältnis zu ihrem literarischen Medium zu setzen. Er will dem Weg, den seine Vorgänger bahnten, folgen, »sed non semper aliena vestigia« [jedoch nicht immer den fremden Fußstapfen] (Petrarca 2017, 344). Der Vers des Horaz, den Egger zitiert, wird von Petrarca angeführt (vgl. Petrarca 2017, 342), allerdings mit der Kautel, dass er selbst gerade »non cum Horatio« (Petrarca 2017, 342) danach trachte, ins Leere zu gehen. Denn trotz der Notwendigkeit, die ruminatio in Grenzen zu halten, ist sie ihm doch die Möglichkeitsbedingung des eigenen Dichtens. Wenn Egger unvermittelt vom Horaz-Zitat zum Wiederkäuen übergeht, wiederholt er eine Geste Petrarcas und markiert in der scheinbar unmotivierten kausalen Verbindung zwischen den beiden Passagen den historischen und poetologischen Ort seines Vorgängers.

\section{Zitat und Abweichung}

Die Genealogie Horaz - Petrarca - Egger stellt sich als ein weiterer Faden in Oswald Eggers komplexer, aus vorgefundenen Materialien gesponnener Dichtung dar. Sie untermauert die These, dass Eggers Werk das Medium der Literatur konsequent in Szene setzt. Das hintergründige Medium der Dichtung perforiert gleichsam die Oberfläche von Eggers Text und kommt ans Licht, so dass der Lesevorgang zwischen Vordergrund und Hintergrund zu oszillieren beginnt. Dieses Spiel zwischen Form und Medium zieht die Aufmerksamkeit der Lesenden auf Eggers Lesearbeit als Bedingung seines Schreibens. Seine Texte fordern eine bei jedem Wort verweilende Lektüre und stellen die Vorurteile etablierter und kaum bewusster hermeneutischer Praktiken auf die Probe. Was eine den Erfordernissen dieser Texte gerecht werdende Lektüre an Selbstverständlichkeit und vermeintlich unmittelbarer Transparenz verliert, gewinnt sie an Selbstreflexivität und multiperspektivischer Anschlussfähigkeit.

44 Das Bienengleichnis und seine Interpretation machen den Hauptteil des 84. Briefes im 11. Buch der an Lucilius gerichteten Epistulae morales aus (Seneca 1999, 224-231). 
Im Leseprozess werden Eggers Formen als kalkulierte Abweichungen kenntlich, durch die sie sich von ihren Vorlagen unterscheiden und sich als Formen in Spannung zu ihrem poetischen Medium erst konstituieren. Das poetische Verfahren der Abweichung bleibt dabei nicht auf poetische Bestände im engeren Sinn beschränkt, sondern betrifft im vorliegenden Fall ebenso geographische und geologische Beschreibungen, die Egger als Ausgangsmaterial für die dichterische Verarbeitung des Val di Non dienen. Denn auch naturwissenschaftliche Befunde können der Sprache nicht entraten und sind als sprachlich verfasste verformbar. Ebenso sind eine große Anzahl von Eggers Zeichnungen, die ungefähr seit der Jahrtausendwende einen zunehmend prominenten Aspekt seiner Bücher ausmachen, Nachzeichnungen, die je nach Fall prominente oder eher unbekannte Vorlagen aus allen möglichen Kultur- und Wissensbereichen mehr oder weniger originalgetreu nachbilden und in neuartige Kontexte transponieren. In allen diesen Fällen, ob Text, ob Bild, handelt es sich nicht um direkte Übernahmen, die, wie Eggers Praxis zeigt, ohnehin in vollem Umfang nie möglich wären, denn jede Iteration weicht ab, und sei es nur, weil nichts zweimal im gleichen Kontext steht.

Imitatio und ruminatio markieren unterschiedliche, aus historischer Perspektive konträre Textumgangsformen. Während die antike Nachahmung darin bestand, sich Texte als Rohstoff für das eigene Schreiben anzueignen, nahm die ruminatio von eigener Textproduktion Abstand und konzentrierte sich als buchstäbliches Exerzitium der Fleischwerdung auf die vollständige Einverleibung des heiligen Wortes und »die Ausbildung eines religiösen Habitus« (Butzer 2007, 49). An der Schwelle zur Neuzeit führt Petrarca die beiden Traditionslinien bewusst zusammen und verweist in diesem Zusammenhang auf jene Verse des Horaz, die auch Egger im Schlusswort von Val di Non zitiert. Schon im Eingang zu Die ganze Zeit ließ Egger seinen Vorgänger ohne Namensnennung erscheinen, allein mittels einer durch Anführungszeichen markierten Stelle innerhalb eines umfangreicheren Zitats, die von Petrarca an einem ausgezeichneten Ort, nämlich auf den Höhen des Mont Ventoux, zitiert wurde (Gilgen 2013, 292f.). Hier wie dort gibt Eggers potenzierte, in sich gefältelte Zitierpraxis der erfahrbaren und mitteilbaren Anwesenheit eines abwesenden Textes den notwendigen Raum. Ohne genannt, nein: ohne gerufen zu werden, stellt sich Petrarca in Eggers Texten ein - dasselbe gilt für Horaz, Hölderlin, Mallarmé und andere mehr - und stellt ihnen die Aufgabe, seine Beiträge zum Medium der Dichtung zu bewältigen, so wie es der Dichter, der nicht zu Unrecht als erster einer neuen Zeit gilt, mit seinen eigenen antiken und mittelalterlichen Vor-Bildern tat. 


\section{Literaturverzeichnis}

Aristotle: Poetics. In: Aristotle: Poetics. Longinus: On the Sublime. Demetrius: On Style.

Transl. by Stephen Halliwell, W. Hamilton Fyfe, Doreen C. Innes, W. Rhys Roberts. Revised

by Donald A. Russell. Loeb Classical Library 199. Cambridge, Mass. 1995, 1-141.

Barthes, Roland: Mythologies. Paris 1957.

Beer, Georg: Kedron 2. In: Paulys Realencyclopädie der classischen Altertumswissenschaft.

Band 11.1. Stuttgart 1921, 112-114.

Benjamin, Walter: Die Aufgabe des Übersetzers. In: Gesammelte Schriften. Band IV.1. Hrsg. v.

Tillman Rexroth. Frankfurt am Main 1991, 9-21.

Butzer, Günter: Physiologie der Imitation. Zur Vorgeschichte der Genieästhetik. In: Übung und

Affekt. Formen des Körpergedächtnisses. Hrsg. v. Bettina Bannasch und Günter Butzer.

Berlin 2007, 43-69.

Egger, Oswald: Nichts, das ist. Frankfurt am Main 2001.

Egger, Oswald: -broich. Homotopien eines Gedichts. Wien 2003.

Egger, Oswald: Prosa, Proserpina, Prosa. Frankfurt am Main 2004.

Egger, Oswald: Diskrete Stetigkeit. Poesie und Mathematik. Frankfurt am Main 2008.

Egger, Oswald: Die ganze Zeit. Berlin 2010.

Egger, Oswald: Val di Non. Berlin 2017.

Frederick, Samuel: Dividing Zero. Beholding Nothing. In: SubStance 35.2 (2006), 71-82.

Gilgen, Peter: Literature in the Age of the Media System. In: Literatur inter- und transmedial /

Inter- and Transmedial Literature. Hrsg. v. David Bathrick und Heinz-Peter Preußer.

Amsterdam 2012, 33-60.

Gilgen, Peter: Reading Time. Oswald Egger's Die ganze Zeit. In: The Germanic Review. 88.3

(2013), 286-304.

Gmelin, Hermann: Das Prinzip der Imitatio in den romanischen Literaturen der Renaissance

(I. Teil). In: Romanische Forschungen 46.1 (1932), 83-360.

Goodman, Nelson: Languages of Art. Indianapolis, Ind. 1976.

Grimm, Jacob und Wilhelm Grimm: Deutsches Wörterbuch. 33 Bde. München 1984.

Heidegger, Martin: Der Spruch des Anaximander. In: Holzwege. Frankfurt am Main 1980, 321-374.

Heidegger, Martin: Hölderlins Hymne »Der Ister«. Freiburger Vorlesung Sommersemester 1942. Gesamtausgabe Bd. 53. Hrsg. v. Walter Biemel. Frankfurt am Main 1984.

Hesiod: Theogony. Works and Days. Testimonia. Hrsg. v. Glenn W. Most. Loeb Classical Library

57. Cambridge, MA 2018.

Hölderlin, Friedrich: Sämtliche Gedichte. Hrsg. v. Jochen Schmidt. Frankfurt am Main 2005.

Horace (Quintus Horatius Flaccus): Satires, Epistles and Ars Poetica. With an English

Translation by H. Rushton Fairclough. Loeb Classical Library 194. Cambridge, Mass. 1929.

Jakobson, Roman: Linguistics and Poetics. In: Language in Literature. Hrsg. v. Krystyna

Pomorska und Stephen Rudy. Cambridge, MA 1987, 62-94.

Jarvis, Simon: For a Poetics of Verse. In: Publications of the Modern Language Association

125.4 (2010), 931-935.

Kant, Immanuel: Kritik der praktischen Vernunft. In: Gesammelte Schriften.

Akademieausgabe. Bd. 5. Berlin 1913, 1-163.

Luhmann, Niklas: Das Kunstwerk und die Selbstreproduktion der Kunst. In: Schriften zu Kunst und Literatur. Hrsg. v. Niels Werber. Frankfurt am Main 2008a, 139-188. 
Luhmann, Niklas: Das Medium der Kunst. In: Schriften zu Kunst und Literatur. Hrsg. v. Niels Werber. Frankfurt am Main 2008b, 123-138.

Luhmann, Niklas: Einführung in die Systemtheorie. Hrsg. v. Dirk Baecker. Heidelberg 2008c. Nietzsche, Friedrich: Unzeitgemäße Betrachtungen II. In: Kritische Studienausgabe. Bd. 1. Hrsg. v. Giorgio Colli und Mazzino Montinari. München 1988, 243-334.

Ovid (Publius Ovidius Naso): Metamorphoses, Volume II: Books 9-15. Translated by Frank Justus Miller. Loeb Classical Library 43. Cambridge, MA 1958.

Ovid (Publius Ovidius Naso): Metamorphoses, Volume I: Books 1-8. Translated by Frank Justus Miller. Revised by G. P. Goold. Loeb Classical Library 42. Cambridge, MA 1977.

Paul, Jean: Das Kampaner Tal oder über die Unsterblichkeit der Seele nebst einer Erklärung der Holzschnitte unter den 10 Geboten des Katechismus. In: Sämtliche Werke, Abteilung 1, Bd. 4. Hrsg. v. Norbert Miller. Darmstadt 2000, 561-716.

Petrarca, Francesco: Selected Letters. Volume I. Translated by Elaine Fantham. Cambridge, MA 2017.

Petri, Bernhard: Das Ganze der Schafzucht für Deutschlands Klima und das ihm ähnliche der angränzenden Länder mit besonderer Hinsicht auf die zu beobachtende Pflege und Wartung der Merinos und Charakterisirung derselben. 2 Bde. Wien 1825.

Peyer, Johann Conrad: Merycologia; sive, De ruminantibus et ruminatione commentaries. Basel 1685.

Plato: Symposium. In: Complete Works. Hrsg. v. John M. Cooper. Indianapolis, IN 1997, 457-505.

Quintilian: The Orator's Education, Volume IV: Books 9-10. Hrsg. v. Donald A. Russell. Loeb Classical Library 127. Cambridge, MA 2002.

Saussure, Ferdinand de: Cours de linguistique générale. Hrsg. v. Tullio de Mauro. Paris 1982.

Seneca, Lucius Annaeus: Seneca Lucilio suo salutem. In: Ad Lucilium Epistulae Morales LXX-CXXIV, [CXXV]. In: Philosophische Schriften. Lateinisch und Deutsch. 4. Bd. Hrsg. v. Manfred Rosenbach. Darmstadt 1999. 222-231.

Spencer Brown, George: Laws of Form. London 1969.

Vattimo, Gianni: „Verwindung «: Nihilism and the Postmodern in Philosophy. In: SubStance, 16.2 (1987), 7-17.

Virgil (Publius Vergilius Maro): Eclogues. Georgics. Aeneid: Books I-VI. With an English Translation by H. Rushton Fairclough, revised by G. P. Goold. Loeb Classical Library 63. Cambridge, MA 1999.

Voß, Johann Heinrich: Quintus Horatius Flaccus. Satyren und Episteln. Werke. Bd. 2. Heidelberg 1806.

Wellbery, David E.: Das Gedicht. Zwischen Literatursemiotik und Systemtheorie. In: Systemtheorie der Literatur. Hrsg. v. Jürgen Fohrmann und Harro Müller. München 1996, 366-383.

Wieland, Christoph Martin: Horazens Briefe aus dem Lateinischen übersezt und mit historischen Einleitungen und andern nöthigen Erläuterungen versehen. In: Werke. Historisch-kritische Ausgabe. Hrsg. v. Klaus Manger und Jan Philipp Reemtsma. Bd. 17.1. Berlin 2008, 39-535.

Wittgenstein, Ludwig: Tractatus logico-philosophicus. Frankfurt am Main 1982.

Young, Arthur: Travels During the Years 1787, 1788, and 1789. Undertaken More Particularly with a View of Ascertaining the Cultivation, Wealth, Resources, and National Prosperity, of the Kingdom of France. London 1792. 
